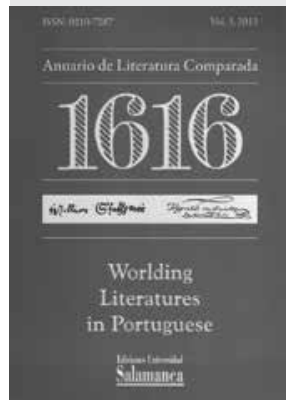

\title{
La revista 1616 y \\ la Sociedad Española de Literatura General y Comparada
}

\author{
Antonio Cruz Casado • \\ Universidad Complutense de Madrid
}

La Sociedad Española de Literatura General y Comparada (SELGYC) tiene sus raíces en la Universidad Complutense de Madrid, la cual junto con otras instituciones españolas y norteamericanas organizó el I Coloquio de Literatura Comparada. Este tuvo lugar durante los días 3 y 4 de abril de 1974, tal como recuerda el profesor Francisco López Estrada en el volumen primero del Anuario 1616, publicación que se convirtió durante décadas en el órgano de expresión de la institución citada y que recuerda, en la denominación, el año en que fallecen dos grandes autores, William Shakespeare y Miguel de Cervantes.

Algún tiempo después, en 1977, en la Universidad de Barcelona y bajo la dirección del profesor Martín de Riquer, se celebra el I Simposio de Literatura Comparada, de lo que también hay noticia y textos en el volumen citado de la revista 1616. Así surge el volumen inicial de la SELGYC, que vio la luz en 1978, en el que se incluye una selección de las ponencias que tuvieron lugar en ambos congresos de Madrid y Barcelona. Figuras muy significativas del comparatismo español, además de los profesores citados, serían Claudio Guillén o Antonio Vilanova, que ya incluyen estudios en este ejemplar.

En los números siguientes, hasta el año 2006 (con diversos saltos temporales, que no vamos a resaltar), año en que aparece publicado el volumen XII, hay significativas colaboraciones de críticos que proceden de los diversos ámbitos del hispanismo, tanto literario como lingüístico, profesores ubicados en diversas universidades españolas y otros centros de estudio, entre los que se encuentran, por citar algunos relevantes, Carlos García Gual, investigador del mundo grecolatino y medieval, o Leonardo Romero Tobar, que centra su atención en el siglo XIX.

Lo que puede considerarse la primera etapa de la publicación termina con el mencionado número del año 2006; en 2011 se reanuda el Anuario de Literatura Comparada y, hasta el momento (2018), tenemos constancia de, al menos, seis volúmenes más: el número 6 corresponde al año 2016.

Los contenidos de esta revista son muy variados y responden, sobre todo en los años centrales de la primera etapa, a los temas propuestos como objeto de estudio en los diversos congresos que viene realizando la SELGYC. Por lo general, se señalan tres temas a los participantes, todos ellos relacionados con el comparatismo y la literatura general, aunque no todas las ponencias pasan luego al anuario 1616, sino que pueden

\footnotetext{
- Catedrático de Lengua y Literatura Española, Doctor en Filología Hispánica por la Universidad Complutense de Madrid, Académico Numerario de la Real Academia de Ciencias, Bellas Letras y Nobles Artes de Córdoba, Miembro de la Sociedad de Literatura General y Comparada y Cronista Oficial de Iznájar y de Lucena.
} 
editarse de forma independiente en volúmenes sueltos, de carácter monotemático, de lo que es ejemplo, entre varios más, el volumen El relato intercalado (Madrid, 1992) o las mismas actas de determinados congresos que ven la luz igualmente sin conexión visible con el citado anuario, órgano de expresión habitual de la Sociedad. De esto último da fe, entre otros muchos casos (y perdóneseme la autocita), el volumen del que fui co-responsable: Estudios de Literatura Generaly Comparada (Lucena, 2009), coordinado por Antonio Cruz y Margit Raders, correspondiente al XVI Simposio de la SELGYC, en el que se incluyen aportaciones sobre los temas «Literatura y alianza de civilizaciones», «Prólogo y paratextos» $\mathrm{y}$ «Bohemios, raros y olvidados».

Con respecto a los contenidos del anuario, podemos señalar una serie de bloques temáticos que nos parecen de singular interés y variedad, entre los que destacamos los siguientes: «Exilio y literatura», «Teoría y crítica literaria» $\mathrm{y}$ «El ensayo como género literario» (VI-VII, 1988); «Filosofía y literatura» $\mathrm{y}$ "Cine y literatura» (VIII, 1990); «Literatura comparada» (IX, 1995); «Ficción histórica», «Locos y simples en la literatura y en el arte» $\mathrm{y}$ «Literatura epistolar y géneros literarios» (X, 1996); «Las literaturas hispánicas en el canon europeo» $\mathrm{y}$ "Literatura y crisis de las humanidades» (XI, 2006) y «El mundo medieval en la literatura contemporánea» (XII, 2006).

La SELGYC estuvo dirigida por algunas de las personalidades más significativas del comparatismo español, como Claudio Guillén, Carlos García Gual, Darío Villanueva, actual Director de la Real Academia Española, o Montserrat Cots. En la actualidad figura como director Dámaso López García, Catedrático de la Universidad Complutense de Madrid, como puede comprobarse en la página web de la institución.

La segunda etapa de 1616 (año 2011 y siguientes) ofrece más uniformidad en los contenidos que algunos anuarios de la etapa anterior, así como una presentación diferente y un cambio más científico en lo que se refiere a las normas de presentación de originales, sin excluir por ello estudios de otra temática. Así, por ejemplo, el número 3, correspondiente a 2013, que tenemos a la vista, nos ofrece seis estudios, en inglés, portugués y español, en el apartado «Globalizando la literatura en portugués»; seis estudios más, en la sección «Varia», en los que se tratan diversos aspectos y relaciones temáticas: Leopoldo María Panero y Roberto Bolaño, los paisajes urbanos de Modiano y Debord, el mito de Pigmalión en un autor japonés, Tanizaki Junichiro, o la periodización en la actual poesía española, entre otras cuestiones. Diversas «Notas», un «Informe», sobre el comparatismo en América Latina, y un texto "In Memoriam» del profesor Martín de Riquer, completan el volumen.

En la actualidad, en nuestro mundo globalizado, son fácilmente accesibles, en la página cervantesvirtual.com, los textos que componen la trayectoria de 1616 , desde 1978 a 2006, como hemos indicado, en tanto que se encuentran en la página oficial de la SELGYC diversos contenidos de los anuarios siguientes, como los índices de cada uno de los números.

En conjunto, esta publicación nos parece el esfuerzo más serio, coherente y conseguido de la cultura española en su afán de promover y consolidar en las universidades de nuestro país los estudios de literatura general y comparada.

\section{Cruz Casado, Antonio}

«La revista 1616 y la Sociedad Española de Literatura 